Matriks

metalloproteinaz

enzimlerinin adeziv bağlanmaya etkisi

\section{Effects of matrix metalloproteinase enzyms on adhesive bonding}

\author{
Uzm. Dt. Derya Merve Halaçoğlu \\ Yeditepe Üniversitesi, Diş Hekimliği Fakültesi, \\ Restoratif Diş Tedavisi A.D., İstanbul
}

Prof. Esra Can

Yeditepe Üniversitesi, Diş Hekimliği Fakültesi, Restoratif Diş Tedavisi A.D., İstanbul

Geliş tarihi: 22 Mart 2017

Kabul tarihi: 15 Mayıs 2017

doi: 10.5505/yeditepe.2017.83803

\section{Yazışma adresi:}

Uzm. Dt. Derya Merve Halaçoğlu

Yeditepe Üniversitesi Diş Hekimliği Fakültes

Restoratif Diş Tedavisi Anabilim Dalı, Bağdat Cad.

No:238 34728 Göztepe, İstanbul

Tel: 4449347

E-posta: merve.halacoglu@yeditepe.edu.tr
ÖZET

Matriks metalloproteinaz enzimleri (MMP), dentin matriksinin içinde bulunan proteolitik enzimlerdir ve dentinin organik matriksini hidrolize etme özellikleri vardır. Rezin-dentin bağlanmasının elde edilmesi için dentine asit uygulanması sonrası dentinin kollajen fibrilleri açığa çıkar. Bu açığa çıkan kollajen fibriller MMP'lerin başlattığı hidrolitik bozulmadan etkilenebilir ve bunun sonucunda bağlanma dayanımında azalma olarak restorasyonların ağız içerisindeki uzun dönem performansı negatif etkilenebilir. Bu derlemenin amacı, dentin kaynaklı MMP'lerin dentin matriks bozulmasındaki rolünün anlaşılması ve kollajen bozulmasını inhibe eden MMP inhibitörlerinin dentinin bağlanma dayanımına etkisinin özetlenmesidir.

Anahtar Kelimeler: Matriks metalloproteinazlar, dental adezivler, kollajen

\section{SUMMARY}

Matrix metalloproteinase enzymes (MMP) are proteolytic enzymes that found in dentin matrix and they are capable to hydrolyze organic matrix of dentin. Dentin collagen fibrils are exposed after acid etching of dentin in order to achieve resin-dentin bonding. These exposed collagen fibrils might be effected by hydrolytic degradation caused by MMP's resulting reduced bonding strength and long-term performance in oral cavity. The purpose of this review is to understand the role of MMP's in dentin matrix degradation and to summarize the effects of MMP inhibitors that inhibits the collagen degradation to dentin bonding strength.

Key words: Matrix metalloproteinases, dental adhesives, collagen

\section{GíRiş}

Restoratif diş hekimliği alanında yapılan pek çok çalıșma ve yeni geliștirilen materyallere rağmen, dentin-adeziv ara yüzeyi diş restorasyon kompleksindeki en zayıf nokta olma özelliğini korumaktadır. Rezin-dentin bağlanmasının elde edilmesi için dentin yüzeyinin fiziksel ve kimyasal özelliklerini değiştirecek birkaç uygulama yapılması gerekir.

Kavite preparasyonu sırasında dentin yüzeyinde oluşan $1-2 \mu \mathrm{m}$ kalınlığında smear tabakası self-etching primer ile modifiye edilir veya \%37'lik fosforik asit ile tamamen ortadan kaldırılır. ${ }^{1}$ Dentinin asitlendiği durumlarda, dentin yüzeyindeki tüm mineral komponent ve smear tabakasının altında bulunan $5 \mu \mathrm{m}$ kalınlıkta mineralize dentin çözünür ve böylece altta bulunan tip I kollajen fibril ağı açığa çıkar. ${ }^{2}$ Kollajen fibriller arasında oluşan boşluğa interfibriler alan adı verilir ve bu boşluk adeziv komonomerleri için difüzyon kanalları oluşturur. ${ }^{3}$ Adeziv komonomerleri demineralizasyon derinliği boyunca ilerleyerek hibrit tabakasını oluşturur. ${ }^{4}$ Idealde hibrit tabakasının uzun yıllar boyunca sağlam kalması beklenir, ancak zamanla hidrolitik çözünmeden dolayı adeziv ara yüzeyde bozulmalar meydana gelebilir. 
Adeziv ara yüzeyinin bozulması sonucunda oluşan mikro boşluklara patojenler penetre olabilir. Mikroorganizma, esteraz ve dental biyofilm varlığında adeziv ara yüzeyinde yıkım meydana gelebilir ve bütün bu olaylar kompozit restorasyonun başarısızlığı ile sonuçlanır. ${ }^{5,6}$ Son zamanlarda yapılan çalışmalarda kompozit restorasyonların en önemli başarısızlık nedenleri sekonder çürük ve diş, restorasyon veya her ikisinde meydana gelen kırık olarak gösterilmektedir.7 Sekonder çürük oluşumunda adeziv ara yüzünde zamanla meydana gelen bozulma özellikle önemlidir ve bu nedenle adeziv diş hekimliğinde son dönemlerde yapılan çalışmalarda mine/dentin ve rezin arasındaki bağlanmanın nano seviyede anlaşılması amaçlanmaktadır. ${ }^{8}$

\section{Adeziv Bağlanmanın Bozulması}

Restorasyonların ağız sıvılarına uzun süre maruz kalması ile su, rezin içine penetre olmaya başlar. Su, adeziv polimerlerin hidrolitik çözünmesinde önemli rol oynamaktadır ve bu çözünme sonucunda adeziv bağlanmanın fiziksel özellikleri azalmaktadır. ${ }^{9,10}$ Su alımı, adezivin plastikleşmesine neden olur ve bağlanma dayanımını azaltır. ${ }^{11}$ Hibrit tabakasında, stabil olmayan polimerlerin rezinden uzaklaştıııması ile kollajen fibriller açığa çıkar. Açığa çıkan ve rezin monomerler ile tamamen örtülemeyen fibriller, kollajenolitik enzimlerin yıkımına yatkın oldukları için dentin-rezin bağlanmasının bütünlüğünün bozulmasına neden olur. ${ }^{12,13}$

Nano boyuttaki düzensizliklerin rezin monomerler ile tamamen örtülmesi zor olduğu için hibrit tabakasının alt kısımlarında açıkta kalan kollajen fibriller de bulunabilmektedir. Hidrofobik rezinlerin örtemediği fibriller bozulmaya daha yatkındır. ${ }^{14}$

Hibrit tabakasında iki tip bozulma gözlenmiştir:

1.Interfibriler alandan rezin kaybı

2.Kollajen fibrillerin organizasyonunun bozulması ${ }^{15}$

Hibrit tabakasında gerçekleşen bu bozulmaların ana nedeni matriks metalloproteinaz enzimlerinin (MMP) aktive olmasıdır. Mazzoni ve ark. yaptıkları çalışmada hibrit tabakasında gerçekleşen bozulmayı incelemişler ve hibrit tabakasında MMP-2 ile MMP-9 aktivitesini göstermişlerdir. ${ }^{16}$

\section{Matriks Metalloproteinazlar}

MMP'ler, çinko $\left(\mathrm{Zn}^{2}+\right)$ ve kalsiyum $\left(\mathrm{Ca}^{2}+\right)$ bağımlı endopeptidazdır. ${ }^{17,18} \mathrm{Bu}$ endojenoz enzimler, fibriler ve fibriler olmayan kollajen, fibronektin, laminin ve membran glikoproteinleri gibi ekstrasellüler matriks komponentlerini çözebilir ve bu yüzden birçok biyolojik ve patolojik süreçte önemli rol oynar. Ek olarak aktive olmaları için prodomainin ayrılması, $\mathrm{Zn}^{2}+$ iyonuna ihtiyaç duyulması, spesifik amino asit sekanslarının korunması ve endojen doku inhibitörleri ile enzimatik aktivitelerinin inhibe olması gibi özellikleri vardır. ${ }^{19}$

MMP'ler, diş gelişimi sırasında mineralize dentin matrik- si içinde bulunur. Restoratif işlemler sırasında MMP enzimlerinin ortaya çıkması, dentin-adeziv bağlanmasında başarısızlık sebebi olarak görülmektedir. ${ }^{20,21}$ Nishitani ve ark. yaptıkları in vitro çalışmada, dentine adeziv uygulanmasının ardından tam olarak örtülemeyen hibrit tabakasındaki kollajen fibrillerin bozulduğunu veya yok olduğunu göstermişlerdir. ${ }^{22}$ Kısmi demineralize dentinde kollajenolitik ve jelatinolitik aktivitenin gerçekleşmesi MMP'lerin varlığının indirekt göstergesidir. Dentin-pulpa kompleksinde MMP'lerin varlığının direkt göstergesi ise zimografi ve Western Blot teknikleri ile enzimlerin gösterilmesidir. $^{20,23}$

Dentin pulpa kompleksinde en az beş adet MMP tespit edilmiştir:

- Stromelisin-1 (MMP-3)

- Kollajenaz (MMP-8)

- Jelatinaz A (MMP-2)

- Jelatinaz B (MMP-9)

- Enamelizin (MMP-20)

Asitle pürüzlendirilen dentin matriksi, dentin kaynaklı proteolitik enzimler ile zamanla bozulur. Son zamanlarda yapılan çalışmalarda konak kaynaklı proteazların, matriks kollajenlerinin bozulmasına neden olarak diş çürüğü patogenezisinde rol aldıkları kanıtlanmıştır. ${ }^{23,24}$ Pashley ve ark. dentin kaynaklı MMPlerin rezin infiltrasyonu zayıf olan hibrit tabakasında bozulmaya neden olduğunu ve bu bozulmanın MMP inhibitörleri ile engellenebileceğini göstermiştir. ${ }^{12}$

Son zamanlarda adeziv bağlanmanın bozulmasını engellemek ve restorasyonların ömrünü uzatmak için yeni stratejiler geliştirilmiştir. ${ }^{25,26} \mathrm{Bu}$ amaçla ekzojenöz MMP inhibitörleri kullanılmaktadır. Sentetik MMP inhibitörleri, MMP'deki $Z^{2}{ }^{2}+$ iyonları ile etkileşime geçen karboksilik asit gibi fonksiyonel gruplar içermektedir. ${ }^{27}$

\section{MMP İnhibitörleri \\ Klorheksidin (CHX)}

$\mathrm{CHX}$ oral mikroorganizmalara karşı geniş spektrumlu aktivite gösterdiği için diş hekimliğinde antimikrobiyal ajan olarak kullanımı yaygın bir ajandır ve geçmiş yıllarda adeziv uygulanmasından önce kavite dezenfektanı olarak kullanımı önerilmiştir. Bu amaçla $\mathrm{CHX}$ uygulanmış dentin yüzeyinin taramalı elektron mikroskop (SEM) görüntüleri incelendiğinde, pürüzlendirilmiş dentin yüzeyinde tutunan CHX kalıntıları gözlenmiş, ancak dentin bağlanma dayanımının artmadığı belirtilmiştir. ${ }^{28}$

Son zamanlarda $\mathrm{CHX}$ 'in, adeziv diş hekimliğinde MMP inhibitörü olarak kullanımı gündeme gelmiştir. $\mathrm{CHX}$, MMP'lerin tanımlanmasından sonra dentindeki kollajenolitik enzimlerin inhibisyonunda kullanılan ilk materyal olmuştur. ${ }^{29} \mathrm{CHX}$ etkin olarak MMP-2, MMP-8, MMP-9 ve sistein katepsinleri inhibe etmektedir. ${ }^{29,30}$ Bu özellikleri sayesinde etch\&rinse adeziv sistemleri ile oluşan hibrit 
tabakasının bütünlüğü korunmakta, MMP'lerin indirekt etkisi ile kollajenin bozulması engellenmektedir. ${ }^{31}$

Enzim inhibisyonu ile adeziv bağlanmayı kuvvetlendirmeyi amaçlayan çalışmaların çoğu $\mathrm{CHX}$ ile yürütülmüştür. Pashley ve ark. bakterisiz ortamda kollajen yıkımının gerçekleştiğini kanıtlamışlardır. ${ }^{12}$ Bu yıkımın konak kaynaklı MMP'ler ile olduğunu ve $\mathrm{CHX}$ uygulanması ile MMP inhibisyonunun sağlandığını göstermişlerdir. ${ }^{12}$ Bugüne kadar yapılan çalışmalarda $\mathrm{CHX}$ uygulanmasının, proteolitik enzim inhibisyonu sağlayarak hibrit tabakasındaki kollajen ağın yapısal bütünlüğünü koruduğu gösterilmiştir. ${ }^{19,32}$ Breschi ve ark. fosforik asit ile pürüzlendirme sonrasında $\mathrm{CHX}$ uygulanması yapılmadığında, mineralize dentinde kollajenolitik aktivitenin inhibe olmadığını, CHX uygulanması yapıldığında ise bu aktivitenin inhibe olduğunu göstermiştir. ${ }^{33}$

\section{Etilendiamintetraasetik Asit (EDTA)}

EDTA, kök kanal sisteminin şekillendirilmesi sırasında en sık kullanılan yıkama ajanlardandır. EDTA, smear tabakası ile kaplanmış dentini yüzeysel olarak dekalsifiye eder ancak etkisi sınırlıdır. ${ }^{25}$ EDTA, $\mathrm{Ca}^{2}+$ ve $\mathrm{Zn}^{2}+$ şelantı olarak etki gösterdiği için dentin hidroksiapatitinde bulunan kalsiyum iyonları ile reaksiyona girerek çözülebilir kalsiyum tuzlarını oluşturur. ${ }^{34}$ EDTA'nın şelant ajanı olmasından dolayı MMP'leri de inhibe edeceği düşünülmüştür. ${ }^{19} \mathrm{Bu}$ amaçla insan dentinindeki aktiviteleri incelenmiş, MMP-2 ve MMP-9'a karşı inhibitör etkisi olduğu tespit edilmiştir. ${ }^{25}$ Thompson ve ark. ${ }^{25} \mathrm{MMP}$ inhibisyonu sağlaması için gereken EDTA uygulama süresini incelemişler ve 1, 2 ve $5 \mathrm{dk}$ \%17 EDTA uygulanmasının enzim inhibisyonu sağladığını göstermişlerdir. Tekçe ve ark. ${ }^{26} \mathrm{CHX}$, benzalkonyum klorid ve EDTA'nın MMP inhibisyon etkisini incelemişler, 24 saatlik sürede tüm uygulamalar benzer sonuç göstermiş ve 12 ay suda bekletme sonucunda dentin bağlanma dayanımı değerleri azalsa da CHX ve EDTA uygulanan örneklerin sonuçlarının benzalkonyum kloridden daha iyi olduğunu bulmuşlardır.

Ancak EDTA'nın MMP inhibisyonunda kullanımına dair çelişkiler de mevcuttur. Ajanın dentinden uzaklaşması için çok fazla yıkanması gerekmektedir ve yıkandıktan sonra MMP'leri inhibe edecek EDTA yüzeyde kalmamaktadır. ${ }^{25}$ Böylece EDTA uygulanması ile hibrit tabakasının korunmasının yüzeyel dentin demineralizasyonundan $\mathrm{mı}$ yoksa MMP inhibisyonundan mı gerçekleştiği tam olarak bilinmemektedir. EDTA'nın adeziv bağlanmaya etki mekanizmasını inceleyen daha fazla çalışma gerekmektedir. ${ }^{27}$

\section{Kuaterner Amonyum Tuzları}

Kuaterner amonyum bileşikleri suda çözülebilen moleküllerdir, antimikrobiyal özellikleri vardır ve adeziv sistemlerin içinde de bulunabilirler. Kuaterner amonyum molekülleri, rezin matrikse sabitlendiklerinde belirgin bakteriostatik özellik gösterirler. ${ }^{35}$
CHX gibi, kuaterner amonyum metakrilatlar (12-metakrilooksidodesilpiridiyum -MDPB) da katyoniktir. Tezvergil-Mutluay ve ark. ${ }^{35}$ kuaterner amonyum metakrilatlarının, MMP-inhibisyon potansiyellerini incelemişler ve kuaterner amonyum metakrilat içeren adeziv sistem kullanıldığında hibrit tabakasının daha iyi korunduğunu saptamışlardır. Kuaterner amonyum metakrilatlarlarının MMP-inhibisyon özellikleri CHX ile benzerdir, ancak daha yüksek konsantrasyonlarda kullanılmaları gerekmektedir. ${ }^{35}$

\section{Çapraz Bağ Ajanları}

Çapraz bağ ajanlarının, MMP inhibisyon özellikleri olduğu gösterilmiştir ${ }^{36,37}$ ve demineralize dentinde kollajen yıkımına karşı direnç geliştirmek için kullanıı. ${ }^{20}$

Riboflavin; UVA ile aktive olan, biyouyumlu bir çapraz bağ ajanıdır ve son zamanlarda diş hekimliğinde kullanımı artmıştır. ${ }^{36,37}$ Riboflavin, bağlanma dayanımını arttııı, adeziv ara yüzeyi stabilize eder ve dentin MMPlerini inhibe eder. ${ }^{36,38}$

Proantosiyanidin; doğal olarak oluşan polifenolik bileşenidir, tannin olarak da adlandırılır. Antioksidan özelliği olan çapraz bağ ajanıdır ve toksisitesi düşüktür. ${ }^{27}$ Üzüm çekirdeği ekstresi en çok kullanılan proantosiyanidindir. ${ }^{39}$ Çekme dayanımını, sertliği ve uzun dönem stabiliteyi arttırdığı gösterilmiștir. ${ }^{40}$ Proantosiyanidin, MMPlerin sentezini engeller ve MMP-1 ile MMP-9'un katalitik aktivitesini inhibe eder. ${ }^{41}$

Epasinghe ve ark. ${ }^{42}$ proantosiyanidinin, hibrit tabakasının ve rezin-dentin ara yüzeyinde açığa çıkan kollajen fibrillerin yıkımına etkisini incelemişler, proantosiyanidinin hem dentin MMP'leri hem de sistein katepsinlerini inhibe ettiğini göstermiş ve etkisinin $\mathrm{CHX}^{\prime}$ den daha fazla olduğunu saptamışlardır.

Karbodiimit (1-Ethyl-3- Karbodiimit); stabil bir siyanamid izomeridir. Oldukça düşük sitotoksisitesi vardır ve dentin kollajen yıkımının azalmasında umut vadeden sonuçları vardır. ${ }^{43}$ Çapraz bağlanma özelliği ile dentine bağlanma stabilitesini arttırmaktadır. ${ }^{44}$

Seseogullari-Dirihan ve ark. ${ }^{20}$ demineralize dentin matriksine 1 ve 5 dakika sürelerinde farklı kollajen çapraz bağ ajanları - gluteraldehit, üzüm çekirdeği ekstresi, riboflavin/UVA, sumac berry ekstresi, curcumin - uygulayarak, endojenöz MMPlerin aktivitesini incelemişlerdir. Çalışmanın sonucunda çapraz bağ ajanlarının uygulandığı örneklerde MMP aktivitesinin \%21 ve \%70 arasında düştüğü saptanmıştır. Aynı zamanda MMP-2, MMP-8 ve MMP-9 salınımında da azalma olduğu gösterilmiştir. Bu sonuca göre klinikte, 1 dakika süre ile uygulanan çapraz bağ ajanlarının adeziv bağlanmayı güçlendireceği düşünülmektedir.

\section{Kitosan}

Kitosan, $\beta$-(1-4) D-glukozamin ve $\mathrm{N}$-asetil-D-glukozamin'den oluşan doğal polisakkarit biopolimeridir ve 
antibakteriyel özelliği vardır. Kitosanın yüzeyindeki pozitif yük ile bakteri hücre duvarındaki negatif yük etkileşime girerek bakteri hücresinin geçirgenliğini arttırır, ve bunun sonucunda hücre ölümü gerçekleşir. ${ }^{45}$ Adeziv sistemlere kitosan ve riboflavin eklenmesi ile demineralize dentin dokusu, MMP'lerin hidrolitik ve kollajenolitik yıkımına karşı korunmaktadır. ${ }^{46}$

\section{Tetrasiklinler ve Analogları}

Tetrasiklin, periodontitis tedavisinde yaygın kullanılan antibiyotiklerdendir. Ribozomal seviyede protein sisteinler ile etkileşime girer, ayrıca inflamasyon, imünomodülasyon, hücre çoğalması ve anjiyogenezde biyolojik aktivite gösterir. ${ }^{47}$

Tetrasiklin ve analogları, antimikrobiyal aktiviteden bağımsız olarak MMP'lerin kollajen yıkım aktivitesini de inhibe eder. Bu antibiyotiklerin MMP'deki aktif alanlara $-\mathrm{Ca}^{2}+$ ve $\mathrm{Zn}^{2}+$ - aracılığıyla bağlandığı söylense de hücre dışı matrikste ve hücre içi alanda çok sayıda antimikrobiyal olmayan mekanizma da gerçekleşmektedir. ${ }^{48}$

Asitle pürüzlendirilen dentin yüzeyine, $\% 2$ doksisiklin uygulanması ile kollajenazın ve jelatinazın inhibe olduğu ve adeziv bağlanmanın arttığı gösterilmiştir. ${ }^{49}$ Li ve ark. ${ }^{32}$ asitle pürüzlendirilen dentinde, $\mathrm{CHX}$ ve Minosiklin uygulanmasının MMP inhibisyonuna etkisini incelemişler, her iki MMP inhibitörünün de etkin adeziv bağlanma ve MMP inhibisyonu sağladığını göstermişlerdir.

Literatürde, tetrasiklinlerin ve analoglarının adeziv bağlanmaya etkilerini inceleyen fazla çalışma bulunmamaktadır. MMP'leri inhibe etme potansiyellerinden dolayı bu bileşenler ile daha fazla çalışma yapılmalıdır. Ancak tetrasiklinin, içerdiği bileşenlerden dolayı dişte mor lekeler oluşturabileceği bilinmektedir ve klinik kullanıma uygunluğu araştırıımalıdır. ${ }^{2}$

\section{Galardin}

Galardin, etkili ve geniş spektrumlu hidroksamat tipi sentetik MMP inhibitörüdür ve MMP substratlarının moleküler taklidi olarak dizayn edilmiştir. Bu özellikleri sayesinde MMP'lerin aktif alanlarına girerek kritik öneme sahip $Z \mathrm{n}^{2}+$ atomuna bağlanırlar. ${ }^{19}$ Galardin, birkaç tip MMP'ye karşı etkindir, özellikle dentinde MMP-1, $-2,-8$ ve -9'a karşı güçlü inhibisyon etkisi vardır. ${ }^{2}$

Galardinin MMP inhibisyon etkisi zimografi ve ara yüzey nanosızıntı deneyleri ile gösterilmiştir.19,50 Da Silva ve ark. ${ }^{21}$ farklı MMP inhibitörleri - galardin, batimastat, GM1489, CHX - içeren deneysel adeziv ajanların etkisini incelemişlerdir. Yapılan çalışmanın sonucunda tüm adeziv sistemlerin kullanılan bu ajanlar ile bağlanma özellikleri artmıştır. Ancak GM1489 ve CHX içeren adeziv sistemler en iyi fizikokimyasal özellikleri göstermişler ve adeziv bağlanma stabilitesini 12 ay suda saklamadan sonra da korumuşlardır.

\section{SONUÇ}

Son yıllarda yapılan çalışmalar ile stabil rezin-dentin bağlanmasının elde edilmesinde ve kollajenolitik hidrolize karşı direnç sağlanmasında MMP inhibitörlerinin kullanılmasının restorasyonların ömrünü uzatacağı iddia edilmektedir. Adeziv ara yüz stabilitesinde hala çözülmemiş problemler olsa da, MMP inhibitörlerinin ve piyasadaki mevcut MMP inhibitörlerinin GM6001 (Millipore Ltd., Watford, UK) ve BB94 (British Biotech Ltd., Oxford, UK) adeziv sistemlere ilave edilmesi ile, adeziv restorasyonların stabilizasyonunda umut verici gelişmeler sağlanacağı düşünülmektedir.

\section{KAYNAKLAR}

1. Eldarrat AH, High AS, Kale GM. In vitro analysis of "smear layer" on human dentine using ac-impedance spectroscopy. J Dent 2004; 32: 547-554.

2. Frassetto A, Breschi L, Turco G, Marchesi G, Di Lenarda R, Tay FR, Pashley DH, Cadenaro M. Mechanisms of degradation of the hybrid layer in adhesive dentistry and therapeutic agents to improve bond durability-A literature review. Dent Mater 2016; 32: e41-53.

3. Talungchit S, Jessop JLP, Cobb DS, Qian F, Geraldeli S, Pashley DH, Armstrong SR. Ethanol-wet bonding and chlorhexidine improve resin-dentin bond durability: quantitative analysis using raman spectroscopy. J Adhes Dent 2014; 16: 441-450.

4. Nakabayashi N, Kojima K, Masuhara E. The promotion of adhesion by the infiltration of monomers into tooth substrates. J Biomed Mater Res 1982; 16: 265-273.

5. Bourbia M, Ma D, Cvitkovitch DG, Santerre JP, Finer Y. Cariogenic bacteria degrade dental resin composites and adhesives. J Dent Res 2013; 92: 989-994.

6. Busscher HJ, Rinastiti M, Siswomihardjo $W$, van der Mei HC. Biofilm formation on dental restorative and implant materials. J Dent Res 2010; 89: 657-665.

7. Bortolotto T, Bahillo J, Richoz O, Hafezi F, Krejci I. Failure analysis of adhesive restorations with SEM and OCT: from marginal gaps to restoration loss. Clin Oral Investig 2015; 19: 1881-1890.

8. Ferracane JL. Resin-based composite performance: are there some things we can't predict? Dent Mater 2013; 29: 51-58.

9. Ito S, Hashimoto M, Wadgaonkar B, Svizero N, Carvalho RM, Yiu C, Rueggeberg FA, Foulger S, Saito T, Nishitani $\mathrm{Y}$, Yoshiyama M, Tay FR, Pashley DH. Effects of resin hydrophilicity on water sorption and changes in modulus of elasticity. Biomaterials 2005; 26: 6449-6459.

10. Chiaraputt $S$, Mai $S$, Huffman BP, Kapur R, Agee KA, Yiu CKY, Chan DC, Harnirattisai C, Arola DD, Rueggeberg FA, Pashley DH, Tay FR. Changes in resin-infiltrated dentin stiffness after water storage. J Dent Res 2008; 87: 655660. 
11. Hashimoto M, Ohno H, Kaga M, Endo K, Sano H, Oguchi $\mathrm{H}$. In vivo degradation of resin-dentin bonds in humans over 1 to 3 years. J Dent Res 2000; 79: 1385-1391. 12. Pashley DH, Tay FR, Yiu C, Hashimoto M, Breschi L, Carvalho RM, Ito S. Collagen degradation by host-derived enzymes during aging. J Dent Res 2004; 83: 216-221.

13. Hashimoto $M$, Ohno $H$, Kaga $M$, Sano $H$, Tay FR, Oguchi $H$, Araki $Y$, Kubota M. Over-etching effects on micro-tensile bond strength and failure patterns for two dentin bonding systems. J Dent 2002; 30: 99-105.

14. Wang $Y$, Spencer $P$. Quantifying adhesive penetration in adhesive/dentin interface using confocal Raman microspectroscopy. J Biomed Mater Res 2002; 59: 46-55. 15. Hashimoto M, Ohno H, Sano H, Kaga M, Oguchi H. In vitro degradation of resin-dentin bonds analyzed by microtensile bond test, scanning and transmission electron microscopy. Biomaterials 2003; 24: 3795-3803.

16. Mazzoni A, Pashley DH, Tay FR, Gobbi P, Orsini G, Ruggeri $A$, Carrilho $M$, Tjäderhane $L$, Di Lenarda R, Breschi L. Immunohistochemical identification of MMP-2 and MMP-9 in human dentin: Correlative FEI-SEM/TEM analysis. J Biomed Mater Res A 2009; 88: 697-703.

17. Visse R, Nagase H. Matrix metalloproteinases and tissue inhibitors of metalloproteinases: structure, function, and biochemistry. Circ Res 2003; 92: 827-839.

18. van Strijp AJP, Jansen DC, DeGroot J, ten Cate JM, Everts $\mathrm{V}$. Host-derived proteinases and degradation of dentine collagen in situ. Caries Res 2003; 37: 58-65.

19. Zhang $S$, Kern M. The role of host-derived dentinal matrix metalloproteinases in reducing dentin bonding of resin adhesives. Int J Oral Sci 2009; 1: 163-176.

20. Seseogullari-Dirihan R, Apollonio F, Mazzoni A, Tjaderhane L, Pashley D, Breschi L, Tezvergil-Mutluay A. Use of crosslinkers to inactivate dentin MMPs. Dent Mater 2016; 32: 423-432.

21. da Silva EM, de Sá Rodrigues CUF, de Oliveira Matos MP, de Carvalho TR, dos Santos GB, Amaral CM. Experimental etch-and-rinse adhesive systems containing MMP-inhibitors: Physicochemical characterization and resin-dentin bonding stability. J Dent 2015; 43: 1491 1497.

22. Nishitani $Y$, Yoshiyama $M$, Wadgaonkar $B$, Breschi $L$, Mannello F, Mazzoni A, Carvalho RM, Tjäderhane L, Tay FR, Pashley DH. Activation of gelatinolytic / collagenolytic activity in dentin by self etching adhesives. Eur $\mathrm{J}$ Oral Sci 2006; 114: 160-166.

23. Hedenbjörk-Lager A, Hamberg K, Pääkkönen V, Tjäderhane $L$, Ericson D. Collagen degradation and preservation of MMP-8 activity in human dentine matrix after demineralization. Arch Oral Biol 2016; 68: 66-72.

24. Mazzoni A, Nascimento FD, Carrilho M, Tersariol I, Papa V, Tjäderhane L, Di Lenarda R, Tay FR, Pashley DH, Breschi L. MMP activity in the hybrid layer detected with in situ zymography. J Dent Res 2012; 91: 467-472.

25. Thompson JM, Agee K, Sidow SJ, McNally K, Lindsey K, Borke J, Elsalanty M, Tay FR, Pashley DH. Inhibition of endogenous dentin matrix metalloproteinases by ethylenediaminetetraacetic acid. J Endod 2012; 38: 62-65.

26. Tekçe N, Tuncer S, Demirci M, Balci S. Do matrix metalloproteinase inhibitors improve the bond durability of universal dental adhesives? Scanning 2016; 38: 535-544. 27. Perdigão J, Reis $A$, Loguercio AD. Dentin adhesion and MMPs: A comprehensive review. J Esthet Restor Dent 2013; 25: 21-241.

28. Collares FM, Rodrigues SB, Leitune VC, Celeste RK, Borba de Araújo F, Samuel SM. Chlorhexidine application in adhesive procedures: a meta-regression analysis. $\mathrm{J} \mathrm{Ad-}$ hes Dent 2013; 15: 11-18.

29. Scaffa PM, Vidal CM, Barros N, Gesteira TF, Carmona AK, Breschi L, Pashley DH, Tjäderhane L, Tersariol IL, Nascimento FD, Carrilho MR. Chlorhexidine inhibits the activity of dental cysteine cathepsins. J Dent Res 2012; 91: 420-425

30. Gendron R, Grenier D, Sorsa T, Mayrand D. Inhibition of the activities of matrix metalloproteinases 2,8 , and 9 by chlorhexidine. Clin Diagn Lab Immunol 1999; 6: 437-439. 31. Mazzoni A, Pashley DH, Nishitani Y, Breschi L, Mannello F, Tjäderhane L, Toledano M, Pashley EL, Tay FR. Reactivation of inactivated endogenous proteolytic activities in phosphoric acid-etched dentine by etch-and-rinse adhesives. Biomaterials 2006; 27: 4470-4476.

32. Li H, Li T, Li X, Zhang Z, Li P, Li Z. Morphological effects of MMPs inhibitors on the dentin bonding. Int $\mathrm{J}$ Clin Exp Med 2015; 8: 10793-10803.

33. Breschi L, Mazzoni A, Nato F, Carrilho M, Visintini E, Tjäderhane L, Ruggeri A Jr, Tay FR, Dorigo Ede S, Pashley $\mathrm{DH}$. Chlorhexidine stabilizes the adhesive interface: A 2-year in vitro study. Dent Mater 2010; 26: 320-325.

34. Hülsmann $M$, Heckendorff $M$, Lennon $A$. Chelating agents in root canal treatment: mode of action and indications for their use. Int Endod J 2003; 36: 810-830.

35. Tezvergil-Mutluay A, Agee KA, Uchiyama T, Imazato S, Mutluay MM, Cadenaro M, Breschi L, Nishitani Y, Tay FR, Pashley $\mathrm{DH}$. The inhibitory effects of quaternary ammonium methacrylates on soluble and matrix-bound MMPs. J Dent Res 2011; 90: 535-540.

36. Cova A, Breschi L, Nato F, Ruggeri A Jr, Carrilho $M$, Tjäderhane L, Prati C, Di Lenarda R, Tay FR, Pashley DH, Mazzoni A. Effect of UVA-activated riboflavin on dentin bonding. J Dent Res 2011; 90: 1439-1445.

37. Fawzy AS, Nitisusanta LI, lqbal K, Daood U, Neo J. Riboflavin as a dentin crosslinking agent: ultraviolet $A$ versus blue light. Dent Mater 2012; 28: 1284-1291.

38. Fawzy A, Nitisusanta L, lqbal K, Daood U, Beng LT, Neo J. Characterization of riboflavin-modified dentin collagen matrix. J Dent Res 2012; 91: 1049-1054. 
39. Joshi SS, Kuszynski CA, Bagchi D. The cellular and molecular basis of health benefits of grape seed proanthocyanidin extract. Curr Pharm Biotechnol 2001; 2: 187 200.

40. Castellan CS, Bedran-Russo AK, Karol S, Pereira PNR. Long-term stability of dentin matrix following treatment with various natural collagen cross-linkers. $J$ Mech Behav Biomed Mater 2011; 4: 1343-1350.

41. Han B, Jaurequi J, Tang BW, Nimni ME. Proanthocyanidin: a natural crosslinking reagent for stabilizing collagen matrices. J Biomed Mater Res A 2003; 65: 118-124.

42. Epasinghe DJ, Yiu CKY, Burrow MF, Hiraishi N, Tay FR. The inhibitory effect of proanthocyanidin on soluble and collagen-bound proteases. J Dent 2013; 41: 832-839.

43. Bedran-Russo AKB, Vidal CMP, Dos Santos PH, Castellan CS. Long-term effect of carbodiimide on dentin matrix and resin-dentin bonds. J Biomed Mater Res B Appl Biomater 2010; 94: 250-255.

44. Mazzoni A, Angeloni V, Apolonio FM, Scotti N, Tjäderhane L, Tezvergil-Mutluay A, Di Lenarda R, Tay FR, Pashley $\mathrm{DH}$, Breschi L. Effect of carbodiimide (EDC) on the bond stability of etch-and-rinse adhesive systems. Dent Mater 2013; 29: 1040-1047.

45. Elsaka S, Elnaghy A. Effect of addition of chitosan to self-etching primer: antibacterial activity and push-out bond strength to radicular dentin. J Biomed Res 2012; 26: 288-294.

46. Daood U, Iqbal K, Nitisusanta LI, Fawzy AS. Effect of chitosan/riboflavin modification on resin/dentin interface: spectroscopic and microscopic investigations. J Biomed Mater Res A 2013; 101: 1846-1856.

47. Sulkala M, Wahlgren J, Larmas M, Sorsa T, Teronen O, Salo T, Tjäderhane L. The effects of MMP inhibitors on human salivary MMP activity and caries progression in rats. J Dent Res 2001; 80: 1545-1549.

48. Sorsa $T$, Tjäderhane $L$, Konttinen $Y T$, Lauhio A, Salo T, Lee H-M, Golub LM, Brown DL, Mäntylä P. Matrix metalloproteinases: contribution to pathogenesis, diagnosis and treatment of periodontal inflammation. Ann Med 2006; 38: 306-321.

49. Longhi M, Cerroni L, Condò SG, Ariano V, Pasquantonio $G$. The effects of host derived metalloproteinases on dentin bond and the role of MMPs inhibitors on dentin matrix degradation. Oral Implantol (Rome) 2015; 7: 71-79. 50. Breschi L, Martin P, Mazzoni A, Nato F, Carrilho M, Tjäderhane L, Visintini E, Cadenaro M, Tay FR, De Stefano Dorigo E, Pashley DH. Use of a specific MMP-inhibitor (galardin) for preservation of hybrid layer. Dent Mater 2010; 26: 571-578. 